\title{
The pattern of malocclusion in a sample of orthodontic patients from Turkey
}

\author{
Mevlut Celikoglu ${ }^{1}$, Sema Akpınar ${ }^{1}$, Ibrahim Yavuz ${ }^{2}$ \\ ${ }^{1}$ Research Assistant, Department of Orthodontics, Faculty of Dentistry, Ataturk University, Erzurum, Turkey \\ ${ }^{2}$ Associate Professor, Department of Orthodontics, Faculty of Dentistry, Ataturk University, Erzurum, Turkey
}

\author{
Correspondence: \\ Department of Orthodontics \\ Faculty of Dentistry \\ Ataturk University \\ Erzurum, 25240, TURKEY \\ mevlutcelikoglu@hotmail.com
}

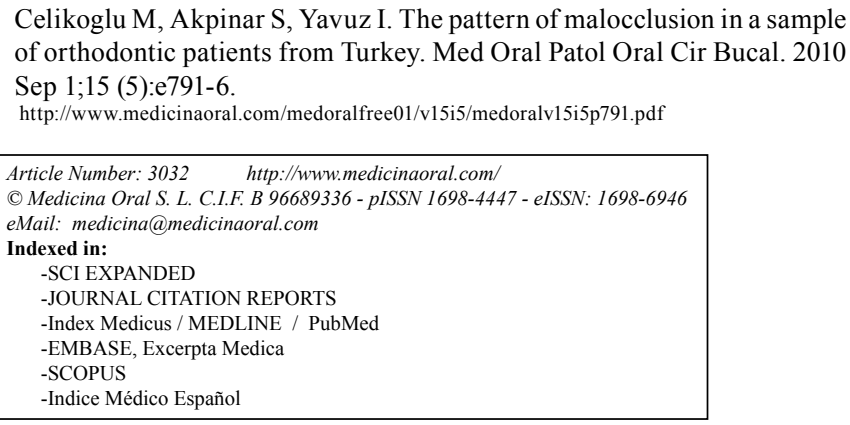

\begin{abstract}
Objective: The objective of this study was to determine the prevalence of individual traits of malocclusion in a sample of Turkish orthodontic patients.

Study design: The present study was based on the examination of dental casts, intraoral photographs and panoramic radiographs of 1507 orthodontic patients (884 females and 623 males). The relationship of the first upper and lower molars according to the Angle's classification, overjet, overbite, crowding, spacing, posterior crossbite, scissor bite, maxillary median diastema were examined. The Pearson chi-squared and Fisher's Exact tests were used to determine potential differences in the distribution of malocclusion when stratified by gender.

Results: The study demonstrated that only $52(3.5 \%)$ of the subjects had normal occlusion. Class I malocclusion was found in 626 (41.5\%), Class II Division 1 in 435 (28.9\%), Class II Division 2 in 142 (9.4\%) and Class III malocclusion in $252(16.7 \%)$ subjects of all examined. Normal overbite, normal overjet, crossbite on both sides and severe crowding in the upper dental arch were observed more frequently in females $(\mathrm{P}<.05)$, however, increased overbite and moderate crowding in the upper dental arch were observed more frequently in males $(\mathrm{P}<.05)$.

Conclusion: The results of this study showed that crowding in the upper and lower dental arches in a sample of Turkish population was the most frequent of all anomalies recorded with ranges of $70.0 \%$ and $47.3 \%$, respectively.
\end{abstract}

Key words: Prevalence, malocclusion, anomalies.

\section{Introduction}

The demand for orthodontic treatment is increasing in most countries (1). Therefore, the epidemiological data on the prevalence of malocclusion is essential in assessing the resources required for orthodontic services and can also provide valuable information regarding the etiology of malocclusions and other complex traits (2).

A large number of studies on the prevalence of maloc- clusion in different ethnic groups have been investigated; including Caucasian (3), Italian (4), non-Hispanic black (5), non-Hispanic white (6), Amerindian (1), and Nigerian (7). The prevalence of malocclusion has been reported to vary from $11 \%$ to $93 \%(8-10)$. These significant variations are difficult to explain. It may depend on differences in registration methods, ethnic origin, social class, or age of the examined subjects (1). However, 
diagnostic criteria are the key factor determining the prevalence of malocclusion (11).

Numerous indices such as IOTN, DAI, and ICON have been developed to rank or score the deviation of malocclusion from the normal $(12,13)$. Most of these indices assess not only the severity of malocclusion but also evaluate the aesthetics. The aesthetic component of the indices is more subjective and less readily measurable than the morphological characteristics (11). The subjectivity of indices used to record orthodontic anomalies, their questionable validity and reliability may contribute to inconsistency of results. An alternative method to the use of indices is a registration of measurable occlusal characteristics such as overjet, overbite, crowding, crossbite, and others.

The aim of this study was, therefore, to determine the prevalence of individual traits of malocclusion, including sagittal molar relationship, posterior crossbite, scissors bite, overjet, overbite, crowding and spacing of upper and lower arches, and maxillary midline diastema in a sample of Turkish orthodontic patients. Furthermore, the data will be useful to compare the results of this study with that of other data reported in different populations.

\section{Materials and Methods}

The present study was based on the examination of dental casts, intraoral photographs and panoramic radiographs of 1507 orthodontic patients from Turkey between January 2005 and January 2008. All data was obtained from the files of orthodontic patients. All patients who met the following inclusion criteria were included in the sample: 1) age 12 to 25 years, 2) secondary dentition present with no remaining deciduous teeth, 3) no multiple missing teeth, 4) presence of first permanent molar and canines, 5) no previous history of orthodontic treatment. Based on the above criteria, a total of 209 dental records were excluded and a final sample of 1507 records of orthodontic patients (884 females and 623 males) with a mean age of $15.9 \pm 2.8$ years were included in this study. Findings were classified in the following criteria:

Sagittal molar relationship was classified Normal occlusion, Class I malocclusion, Class II Division I, Class II Division II and Class III malocclusions. Patients that deviated from the Class I relationship as described by Angle (14) (including crowding, spacing, rotation and abnormal overjet and overbite) were categorized as Class I malocclusion. Therefore, the Class I normal category was limited to patients with ideal or near ideal occlusions. Patients with a different Angle classification of occlusion on each side were categorized into a single class based on the predominant pattern of occlusion and/or canine relationship. Posterior crossbite and scissors bite were evaluated assessing transversal relation- ship of the upper and lower premolar and molar teeth and registered as bilateral, right and left $(1,10,15)$.

Overjet, the distance between the edge of the upper central incisor and the labial surface of the lower central incisor, was measured in millimeters. The overjet between 1.1 and $3 \mathrm{~mm}$ were considered normal, greater than 3 $\mathrm{mm}$ was considered increased, and less than $1 \mathrm{~mm}$ was taken as edge to edge. The term negative overjet was used if both the left and right maxillary central incisors were in palatal occlusion $(1,10,16)$. Overbite, the perpendicular distance from the edge of the central lower incisor to the upper central incisor edge, was measured in millimeters and considered as normal between 0 and $3 \mathrm{~mm}$. Greater than $3 \mathrm{~mm}$ was considered as deep bite, less than $0 \mathrm{~mm}$ as open bite $(1,10,11,13,16)$.

Surplus space in the upper and lower dental arches exceeding $2 \mathrm{~mm}$ was considered as spacing $(10,11)$. Crowding of upper and lower arches was measured in millimeters and considered as no crowding between 0 and $2 \mathrm{~mm}$, mild crowding between 2.1 and $4.0 \mathrm{~mm}$, moderate crowding between 4.1 and $7.0 \mathrm{~mm}$, and severe crowding more than $7 \mathrm{~mm}(10,11)$. Maxillary midline diastema was diagnosed when there was a space of at least $2 \mathrm{~mm}$ between the central incisors in upper arch $(1,10,16)$.

The radiographs were examined by two investigators. To check for the diagnostic reproducibility of interreliability of the 2 examiners, $10 \%$ of the radiographs were examined in random order daily for 3 consecutive days assigned by them. Examination of results with the Wilcoxon matched-pairs signed rank test showed no statistically significant differences between the 2 observers, indicating diagnostic reproducibility. In addition, 10\% of the remaining radiographs were selected at random and reevaluated twice by the same examiner 6 weeks after the first evaluation. Intra-examiner reproducibility was found to be 96 and $90 \%$, respectively. The variables were analyzed using the Statistical Package for Social Sciences (SPSS 12.0) Program. The Pearson chi-squared and Fisher's Exact tests were used to determine potential differences in the distribution of dental anomalies when stratified by gender.

\section{Results}

The study demonstrated that only 52 (3.5\%) subjects had Normal occlusion. Class I malocclusion was found in 626 subjects, which represented $41.5 \%$ of the 1507 subjects examined. Class II malocclusion was found in 577 subjects; 435 (28.9\%) of all patients were Division 1 and $142(9.4 \%)$ were Division 2. Class III malocclusion was found in $252(16.7 \%)$ subjects. No significant gender differences were found for molar relationship. Crossbite was observed on both sides in $241(16.0 \%)$ of the subjects examined, mostly observed in females $(\mathrm{P}<.05)$ (Table 1). It was more commonly found unilaterally on 
the right than left side. A scissor bite was observed only in 7 subjects with a range of $0.5 \%$, with no statistically significant sexual difference. Of those, 2 were observed bilaterally and 5 unilaterally (Table 1).

Distribution of overjet and overbite was shown in (Table 2). The most frequently diagnosed finding for overjet was an increased overjet in $628(41.7 \%)$ of all patients examined. Normal overjet was found in $484(32.1 \%)$ subjects, with a higher prevalence in females $(\mathrm{P}<.05)$. The prevalence of the negative overjet $(14.1 \%)$ was higher than edge to edge $(12.1 \%)$ values. Normal overbite was the most common pattern of overbite and mostly observed in females $(\mathrm{P}<.05)$. Increased overbite was recorded in $36.6 \%$ of the patients and mostly observed in males $(\mathrm{P}<.001)$. The prevalence of open bite was $10.0 \%$.
It was observed mostly in females, but no statistically significant sexual difference was found $(\mathrm{P}>.05)$.

Spacing in the upper and lower dental arches was detected in $96(6.4 \%)$ and $188(12.5 \%)$ subjects, respectively. No significant gender differences were found for spacing in the upper and lower arches $(\mathrm{P}>.05)$. Crowding in the upper and lower dental arches was detected in 1055 (70.0\%) and $713(47.3 \%)$ of the subjects, respectively. In the upper dental arch, moderate crowding was more frequently found in males $(\mathrm{P}<.05)$ and severe crowding in females $(\mathrm{P}<.05)$. Moderate crowding was the most common finding for upper dental arch but mild crowding for lower dental arch. Midline diastema was observed in 68 $(4.5 \%)$ of the patients. It was almost equally distributed between the females and males, 35 in females and 33 in males (Table 3).

Table 1. The distribution of sagittal molar relationship, posterior crossbite, scissors bite.

\begin{tabular}{|c|c|c|c|c|c|c|c|}
\hline & Female & Male & Total & & $\mathbf{P}$ \\
\hline \multirow{5}{*}{\multicolumn{2}{|c|}{ Molar relationship }} & Class I & $363(41.1 \%)$ & $263(42.2 \%)$ & $626(41.5 \%)$ & NS & 0.655 \\
\hline & & Class II Divison 1 & $256(29.0 \%)$ & $179(28.7 \%)$ & $435(28.9 \%)$ & NS & 0.924 \\
\hline & & Class II Division 2 & $80(9.0 \%)$ & $62(10.0 \%)$ & $142(9.4 \%)$ & NS & 0.555 \\
\hline & & Class III & $157(17.8 \%)$ & $95(15.2 \%)$ & $252(16.7 \%)$ & NS & 0.198 \\
\hline & & Normal occlusion & $28(3.2 \%)$ & $24(3.9 \%)$ & $52(3.5 \%)$ & NS & 0.473 \\
\hline \multirow{4}{*}{ Crossbite } & \multicolumn{2}{|c|}{ No crossbite } & $593(67.1 \%)$ & $440(70.6 \%)$ & $1033(68.5 \%)$ & NS & 0.144 \\
\hline & \multicolumn{2}{|l|}{ Bilateral } & $160(18.1 \%)$ & $81(13.0 \%)$ & $241(16.0 \%)$ & $* *$ & 0.008 \\
\hline & \multirow[b]{2}{*}{ Unilateral } & Right & $68(7.7 \%)$ & $63(10.1 \%)$ & $131(8.7 \%)$ & NS & 0.101 \\
\hline & & Left & $59(6.7 \%)$ & $36(5.8 \%)$ & $95(6.3 \%)$ & NS & 0.481 \\
\hline \multirow{3}{*}{ Scissorbite } & \multicolumn{2}{|l|}{ Bilateral } & $1(0.1 \%)$ & $1(0.2 \%)$ & $2(0.1 \%)$ & NS & 0.803 \\
\hline & \multirow{2}{*}{ Unilateral } & Right & $1(0.1 \%)$ & $0(0.0 \%)$ & $1(0.1 \%)$ & NS & $0.586^{*}$ \\
\hline & & Left & $2(0.2 \%)$ & $2(0.3 \%)$ & $4(0.3 \%)$ & NS & $0.548^{*}$ \\
\hline
\end{tabular}

NS: Not significant; *: Fisher's Exact test; **: $\mathrm{P}<.01$

Table 2. The distribution of overjet and overbite.

\begin{tabular}{|l|l|c|c|c|c|c|}
\hline \multirow{5}{*}{ overjet } & \multicolumn{2}{|c|}{ Female } & Male & Total & & \multirow{2}{*}{ P } \\
\hline & Normal & $303(34.3 \%)$ & $181(29.1 \%)$ & $484(32.1 \%)$ & $*$ & 0.032 \\
\cline { 2 - 8 } & Increased & $357(40.4 \%)$ & $271(43.5 \%)$ & $628(41.7 \%)$ & NS & 0.227 \\
\cline { 2 - 8 } & Edge to edge & $102(11.5 \%)$ & $80(12.8 \%)$ & $182(12.1 \%)$ & NS & 0.445 \\
\cline { 2 - 8 } & Negative & $122(13.8 \%)$ & $91(14.6 \%)$ & $213(14.1 \%)$ & NS & 0.658 \\
\hline \multirow{5}{*}{ overbite } & Normal & $501(56.7 \%)$ & $305(49.0 \%)$ & $806(53.5 \%)$ & $* *$ & 0.003 \\
\cline { 2 - 8 } & Increased & $284(32.1 \%)$ & $267(42.9 \%)$ & $551(36.6 \%)$ & $* * *$ & 0.0001 \\
\cline { 2 - 8 } & $\begin{array}{l}\text { Open bite } \\
\text { (Negative) }\end{array}$ & $99(11.2 \%)$ & $51(8.2 \%)$ & $150(10.0 \%)$ & NS & 0.054 \\
\hline
\end{tabular}

NS: Not significant; *: $\mathrm{P}<.05 ; * *: \mathrm{P}<.01 ; * * *: \mathrm{P}<.001$. 
Table 3. The distribution of spacing and crowding in the upper and lower dental arches, and midline diastema.

\begin{tabular}{|c|c|c|c|c|c|c|c|}
\hline & & & Female & Male & Total & & $\mathbf{p}$ \\
\hline Spacing & \multirow{5}{*}{ Upper arch } & present & $54(6.1 \%)$ & $42(6.7 \%)$ & $96(6.4 \%)$ & NS & 0.620 \\
\hline \multirow{4}{*}{ Crowding } & & no & $194(22.0 \%)$ & $162(26.0 \%)$ & $356(23.6 \%)$ & NS & 0.067 \\
\hline & & mild & $214(24.2 \%)$ & $136(21.8 \%)$ & $350(23.2 \%)$ & NS & 0.282 \\
\hline & & moderate & $254(28.7 \%)$ & $138(22.2 \%)$ & $392(26.0 \%)$ & $* *$ & 0.004 \\
\hline & & severe & $168(19.0 \%)$ & $145(23.3 \%)$ & $313(20.8 \%)$ & $*$ & 0.044 \\
\hline Spacing & \multirow{5}{*}{ Lower arch } & present & $103(11.7 \%)$ & $85(13.6 \%)$ & $188(12.5 \%)$ & NS & 0.249 \\
\hline \multirow{4}{*}{ Crowding } & & no & $355(40.2 \%)$ & $251(40.3 \%)$ & $606(40.2 \%)$ & NS & 0.959 \\
\hline & & mild & $221(25.0 \%)$ & $132(21.2 \%)$ & $353(23.4 \%)$ & NS & 0.085 \\
\hline & & moderate & $147(16.6 \%)$ & $100(16.1 \%)$ & $247(16.4 \%)$ & NS & 0.765 \\
\hline & & severe & $58(6.5 \%)$ & $55(8.8 \%)$ & $113(7.5 \%)$ & NS & 0.100 \\
\hline \multirow{2}{*}{\multicolumn{2}{|c|}{ Midline diastema }} & Absent & $849(96.0 \%)$ & $590(94.7 \%)$ & $1439(95.5 \%)$ & NS & 0.218 \\
\hline & & Present & $35(4.0 \%)$ & $33(5.3 \%)$ & $68(4.5 \%)$ & NS & 0.218 \\
\hline
\end{tabular}

NS: Not significant; *: $\mathrm{P}<.05 ; * *: \mathrm{p}<.01$.

\section{Discussion}

Although many studies have been published that describe the prevalence and types of malocclusion, it is difficult to compare and contrast these findings, in part because of the varying methods and indices used to assess and record occlusal relationship $(1,11,17)$. Other variables (including age differences of the study populations, examiner subjectivity, specific objectives, and differing sample sizes) further complicate efforts to understand and appreciate the differences recorded in patterns of malocclusion between ethnic groups $(1,18)$.

Because it is stated that the prevalence of different types of malocclusions may show great variability even in a population of the same origin (13), the selection criteria for individual traits for malocclusion used in this study was collected from the studies published in different geological regions of Turkey $(10,13)$ and contemporary populations $(1,4,16,18)$.

In the present study, included a wide population accepted for orthodontic treatment, malocclusion was found to be $96.5 \%$. This value less than the data reported by Gelgor et al. (10) who detected malocclusion in $89.9 \%$ of their study population. The difference might be because of the different material used in both studies. They investigated the prevalence of malocclusion in general subpopulation.

Although Angle's classification is limited in that it does not incorporate vertical and transversal abnormalities, it is a universally accepted system that is reliable and repeatable and that minimizes examiner subjectivity (18). In this study the prevalence of Normal occlusion was found to be only $3.5 \%$ and this value was in agree- ment with the studies reported by Horowitz (17) and Silva and Kang (18). The prevalence of Class I malocclusion $(41.5 \%)$ in the present study was less than the data reported by Silva and Kang (18), Onyeaso (16), and Sidlauskas and Lopatiene (11) who reported that $69.4 \%$, $50.0 \%$ and $68.4 \%$ of the sample examined had Class I malocclusion, respectively. When compared with the studies published in different regions of our country this value is less than the data reported by Sayın Sayın and Turkkahraman (13) (64\%) but more than the data reported by Gelgor et al. (10) (34.9\%). The prevalence of Class II Division 1 (28.9\%) in the present study was very close to that reported by Sidlauskas and Lopatiene (11) $(27.7 \%)$ but more than the data reported by Sayın Sayın and Turkkahraman (13) who reported that $19 \%$ of the subjects had Class II Division 1 maloclusion. The prevalence of Class II Division 2 (9.4\%) was more than the data reported by Gelgor et al. (10) (4.7\%) and Sayın Sayın and Turkkahraman (13) (5.0\%). The prevalence of Class III malocclusion (16.7\%) is close to the prevalences determined by some studies $(10,13,16)$ but more than the data reported by Proffit et al. (19) (5.7\%) and Thilander et al. (1) (5.8\%) and the differences between the prevalences of maloclusions might be related to the material and racial differences.

The present study confirmed that predominant anteroposterior relationship of the arches in examined Turkish subjects was Class I malocclusion, with no significant gender differences. On the other hand, Onyeaso et al. (7) reported that males were found to have significantly more of Class II and III molar relationships than females. 
The data of high prevalence of increased overjet and overbite, in the present study, was in agreement with the data reported by Proffit et al. (19) who reported that $29.6 \%$ had normal overjet and $45.2 \%$ had increased overjet. Additionally, Gelgor et al. (10) found that the prevalences of increased overjet and overbite to be in high frequencies that reflect the high prevalence of Class II malocclusion in Central Anatolian population. On the other hand,females had normal overjet and normal overbite $(\mathrm{P}<.05)$ and males had increased overbite more frequently $(\mathrm{P}<.001)$. This value was in agreement with the study reported by Gelgor et al. (10) who stated the gender differences for normal overbite (more common in females, $\mathrm{P}<.001$ ) and increased overbite (more frequent in males, $(\mathrm{P}<.05)$. The prevalence of open bite $(10.0 \%)$ in this study was less than the data reported by Gelgor et al. (10) (8.2\%) for Central Anatolian population but very close to the data reported by Thilander et al. (1) $(10.7 \%)$ for Bogotanians in Colombia.

In the present study, scissor bite was less frequently observed than crossbite and observed in only $0.5 \%$ of the subjects examined. This low rate of scissor bite was very close to the data reported by Gelgor et al. (10) for Central Anatolian population $(0.3 \%)$ with no significant sexual difference. Bilateral crossbite was the most frequently observed pattern of crossbite and observed more frequently in females than males $(\mathrm{P}<.05)$. One explanation for the high rates of crossbite in the present study might be that our study evaluated the subjects accepted for orthodontic treatment but Gelgor et al. (10) investigated the referred population. On the other hand, the prevalence of the crossbite in a six-year-old schoolchildren population from Argentina was found to be $0.3 \%(20)$. The difference might be due to the material difference.

Crowding in the upper and lower dental arches was the most frequent of all anomalies recorded with ranges of $70.0 \%$ and $47.4 \%$, respectively. This finding complied with the results of Thilander et al. (1) and Gelgor et al. (10) who reported that crowding was the most frequent of all anomalies. In the present study, moderate maxillary crowding was the most common finding in the upper dental arch and mild crowding in the lower dental arch. This was in agreement with the data reported by Sayın Sayın and Turkkahraman (13) who evaluated the population of the Southern Region of Turkey. Gelgor et al. (10) reported that mild crowding was the most common finding in upper and lower dental arches. The difference might be because they evaluated only anterior crowding but not posterior crowding. The prevalence of spacing in this study for upper dental arch (6.4\%) and lower dental arch (12.5\%) was considerably less than the data reported by Thilander et al. (1) (25.9\%). Because the studies published in different regions of Turkey did not evaluate both posterior and anterior segment, we could not compare the results with that of studies $(10,13)$.

Onyeaso (16) found the prevalence of maxillary midline diastema in their population to be $24.0 \%$ and stated that it was not regarded as malocclusion among Nigerians but as a mark of natural beauty. The prevalence of maxillary midline diastema (4.5\%), in the present study, was very close to that of reported by Thilander et al. (1) $(4.0 \%)$, but less than the data reported by Gelgor et al. (10) who reported that $7.0 \%$ of the Central Anatolian population had maxillary midline diastema.

The epidemiological data on the prevalence of malocclusion is an important determinant in planning appropriate levels of orthodontic services and further studies are required to provide accurate estimates of the orthodontic treatment need in Turkish population.

\section{References}

1. Thilander B, Pena L, Infante C, Parada SS, de Mayorga C. Prevalence of malocclusion and orthodontic treatment need in children and adolescents in Bogota, Colombia. An epidemiological study related to different stages of dental development. Eur J Orthod. 2001;23:15367.

2. Rudan I, Campbell H, Rudan P. Genetic epidemiological studies of eastern Adriatic Island isolates, Croatia: objective and strategies. Coll Antropol. 1999;23:531-46.

3. Kerosuo H. Occlusion in the primary and early mixed dentitions in a group of Tanzanian and Finnish children. ASDC J Dent Child. 1990;57:293-8.

4. Ciuffolo F, Manzoli L, D’Attilio M, Tecco S, Muratore F, Festa $\mathrm{F}$, et al. Prevalence and distribution by gender of occlusal characteristics in a sample of Italian secondary school students: a crosssectional study. Eur J Orthod. 2005;27:601-6.

5. Otuyemi OD, Ogunyinka A, Dosumu O, Cons NC, Jenny J. Malocclusion and orthodontic treatment need of secondary school students in Nigeria according to the dental aesthetic index (DAI). Int Dent J. 1999;49:203-10.

6. Brunelle JA, Bhat M, Lipton JA. Prevalence and distribution of selected occlusal characteristics in the US population, 1988-1991. J Dent Res. 1996;75 Spec No:706-13.

7. Onyeaso CO, Aderinokun GA, Arowojolu MO. The pattern of malocclusion among orthodontic patients seen in Dental Centre, University College Hospital, Ibadan, Nigeria. Afr J Med Med Sci. 2002;31:207-11.

8. Vig KW, Fields HW. Facial growth and management of orthodontic problems. Pediatr Clin North Am. 2000;47:1085-123.

9. Willems G, De Bruyne I, Verdonck A, Fieuws S, Carels C. Prevalence of dentofacial characteristics in a belgian orthodontic population. Clin Oral Investig. 2001;5:220-6.

10. Gelgör IE, Karaman AI, Ercan E. Prevalence of malocclusion among adolescents in central anatolia. Eur J Dent. 2007;1:125-31.

11. Sidlauskas A, Lopatiene K. The prevalence of malocclusion among 7-15-year-old Lithuanian schoolchildren. Medicina (Kaunas). 2009;45:147-52.

12. Onyeaso CO, Begole EA. Orthodontic treatment--improvement and standards using the peer assessment rating index. Angle Orthod. 2006;76:260-4.

13. Sayin MO, Türkkahraman H. Malocclusion and crowding in an orthodontically referred Turkish population. Angle Orthod. 2004;74:635-9.

14. Angle E. Classification of malocclusion. Dental Cosmos. 1899;41:248-64.

15. Tausche E, Luck O, Harzer W. Prevalence of malocclusions in the early mixed dentition and orthodontic treatment need. Eur J Orthod. 2004;26:237-44. 
16. Onyeaso CO. Prevalence of malocclusion among adolescents in Ibadan, Nigeria. Am J Orthod Dentofacial Orthop. 2004;126:604-7.

17. Horowitz HS. A study of occlusal relations in 10 to 12 year old Caucasian and Negro children--summary report. Int Dent J. 1970;20:593-605.

18. Silva RG, Kang DS. Prevalence of malocclusion among Latino adolescents. Am J Orthod Dentofacial Orthop. 2001;119:313-5.

19. Proffit WR, Fields HW Jr, Moray LJ. Prevalence of malocclusion and orthodontic treatment need in the United States: estimates from the NHANES III survey. Int J Adult Orthodon Orthognath Surg. 1998;13:97-106

20. Llompart G, Marin GH, Silberman M, Merlo I, Zurriaga O; GIS (Grupo Interdisciplinario para Salud). Oral health in 6-year-old schoolchildren from Berisso, Argentina: falling far short of WHO goals. Med Oral Patol Oral Cir Bucal. 2010;15:e101-5. 